\title{
Changes in Autonomic Nervous System in Patients with Multiple Sclerosis
}

\author{
AHMED S. ALJEFRI, M.D. and YOUNOUS A. BINTALEB, M.D. \\ The Department of Internal Medicine, Faculty of Medicine and Health Sciences, University of Aden, Yemen
}

\begin{abstract}
Background: Multiple sclerosis (MS) is one of the most disabling neurological disorders, in which autonomic impairment is not rare.

Aim of Study: To assess the frequency of cardiovascular (CV) autonomic dysfunction in MS patients as well as to relate these autonomic abnormalities to the brainstem dysfunctions in thoe patients evidenced by brainstem auditory evoked potential (BAEP) studies.

Patients and Methods: We studied 20 patients with clinically definite relapsing remitting MS and 20 gender and age matched healthy control. The patients were evaluated clinically using expanded disability status scale (EDSS). Autonomic functions were evaluated with blood pressure response to both standing and static exercise (sympathetic), and 24-hour electrocardiographic (ECG) recording, time domain (parasympathetic). Brain stem auditory evoked potential was performed to all patients. Data were statistically analyzed using Epi-info software version 6.04 .

Results: The MS patients included $11(55 \%)$ males and nine $(45 \%)$ females with a mean age of $29.8-8.4$ years, whereas control group was composed of five $(50 \%)$ males and five $(50 \%)$ females with a mean age of $34.2 \pm 13.4$ years. Regarding tests of CV autonomic functions, $13(65 \%)$ patients had at least one abnormal test. The results showed statistically significant differences in all CV autonomic tests when comparing MS patients to controls. We found significant correlations between autonomic tests with duration of the disease. Significant correlations were detected between autonomic tests and brainstem lesions. BAEP findings were indicative of brainstem affection and there was a significant correlation between autonomic tests and I-V inter peak latency.
\end{abstract}

Conclusion: These results suggest that a significant number of patients with MS show evidence of CV autonomic dysfunction, which is correlated with brainstem function.

Key Words: Multiple sclerosis - Autonomic nervous system - Brain stem.

\section{Introduction}

AUTONOMIC dysfunction is frequently observed in patients with multiple sclerosis (MS), but the

Correspondence to: Dr. Ahmed S. Alegefry, E-Mail: Algefry0009@ gmail.com significance of these abnormalities and the relationship to clinical characteristics are not yet established [1]. Genitourinary affection which is found in nearly two thirds of the patients occasionally presents early and manifests as urinary urgency and an increased micturition frequency as well as sexual dysfunction leading to impotence [2]. Disturbances of gastrointestinal function, such as absence of the normal post-prandial increase in colonic motility, were also demonstrated [3] . Autonomic cardiovascular dysfunction is an uncommon, but potentially dangerous event [4]. Autonomic dysfunction involving both the sympathetic and parasympathetic systems has been demonstrated in MS using cardiovascular reflex tests based on heart rate and blood pressure responses to various stimuli $[2,5,6,7]$. However these cardiovascular reflex tests show great individual variability, and only provide information obtained from responses to stimuli during short periods under experimental conditions, so alternative methods of evaluations are needed [8]. In this way, heart rate variability (HRV) analysis has been previously used for clinical and research purposes in cardiologic and some neurologic diseases such as MS [9]. Conventional time and frequency domain analysis techniques based on linear fluctuation of the heart rate obtained by $24 \mathrm{~h}$ electrocardiogram (ECG) recording provide useful tools for evaluating quantitatively the tonic autonomic effects on the heart [10-12]. Major heart dysrythmias during acute relapses have, however, been reported to cause clinically relevant events, thus rendering the detection of subclinical autonomic cardiac abnormalities in MS warranted [4] Thus, dynamic measurements of HRV have provided important information on cardio-vascular mortality as some of them have been shown to be more powerful predictors of death than the traditional risk markers [8]. It has been reported that brain stem is an essential region in the regulation of the autonomic cardiovascular functions and 
brain stem auditory evoked potential (BAEP) can contribute to the evaluation of the brain stem integrity and central conduction time. The aim of this study was to assess the frequency of cardiovascular dysfunction as well as the yield of cardiovascular testing for diagnosing the problem in MS patients, when compared to normal subjects using standards tests as blood pressure response to standing and to sustained hand grip (assessing the sympathetic function), beside evaluating $24 \mathrm{~h}$ heart rate variability, time domain which assess the parasympathetic function. We aimed also to correlate this autonomic dysfunction to the brain stem dysfunctions evidenced by brainstem auditory evoked potential study. This study will help in clarifying different aspects in multiple sclerosis that are vague till now.

\section{Patients and Methods}

Sample size:

This study included 20 patients with clinically definite relapsing and remitting MS according to Macdonald criteria, as well as 20 age and sex matched control groups. The patients were selected from new medical center of neurology in Aden from January 2016 to December 2017.

\section{Exclusion criteria:}

Patients with cardiac disease, hypertension (systolic blood pressure over $100 \mathrm{mmHg}$ and diastolic blood pressure over $90 \mathrm{mmHg}$ ), coronary artery diseases, and diabetes mellitus were excluded from the study. At the time of the study neither patients nor controls were receiving drugs known to affect the autonomic system.

\section{Sampling methods:}

Both patients and controls were subjected to thorough neurological examination. Assessment of impairment in patients was done using expanded disability status scale (EDSS). The clinical severity of autonomic failure was graded using a rating scale to assess 11 different modalities of ANS measures (postural dizziness and disturbances of sweating, urinary function, bowel function, sexual function, heart rate regulation, salivation, and breathing and signs of peripheral circulation disturbances, sluggish papillary reactions, and seborrhea); the dysfunction being graded from 0 to 2 ( $0=$ absent, $1=$ mild, 2-moderate to severe) $[8]$

\section{Autonomic function tests:}

\section{Blood pressure tests (sympathetic function):}

A- Blood pressure response to standing: $\mathrm{BP}$ was measured while lying and then standing up with the arm in horizontal position. A drop of systolic pressure $>20 \mathrm{mmHg}$ or a drop of diastolic blood pressure $\geq 10 \mathrm{mmHg}$ is pathognomonic for the diagnosis of postural hypotension 5 .

B-Blood pressure response to static exercise: considering diastolic blood pressure increment of less than $15 \mathrm{mmHg}$ in response to a standardized sustained hand grip to be abnormal.

Heart rate variability (parasympathetic dysfunction):

24-hour electrocardiographic (ECG) recording. After three hour smoking, tea, coffee deprivation, informed consent was obtained from all subjects before testing. A $24 \mathrm{~h}$ Holter recording was obtained in each patient on a flash card using 3-Channel digital monitor. The recordings were analyzed using commercially available software from Diagnostic.

Monitoring, Santa Ana, CA, USA also delivering the flash cards and the monitors. QRS complexes with abnormal morphology were excluded from the HRV analysis and the recordings were processed without knowledge of other patient variables. Tapes of short period were excluded as they are not suitable for HRV analysis. Because of the use of digital technology there were no speed errors in the recordings. The following time domain HRV variables were analyzed [9]:

1-RRI (the mean of all normal RR intervals during the 24-h recording).

2- SDNN (the standard deviation of all normal RR intervals in the entire 24-h Recording )

3- SDNN index (the mean of the standard deviations of all normal RR intervals for all 5-min segments of the 24-h recording).

4- SDANN (the standard deviation of the mean $\mathrm{RR}$ intervals measured in successive 5-min periods).

5- PNN50 (the percentage of successive RR interval differences $>50 \mathrm{~ms}$ ).

6- RMSSD (the square root of the mean of the sum of the squares of differences between adjacent intervals).

7- Max RR-Min RR (the differences between the maximum numbers and the minimum number of normal RR).

\section{Data processing:}

The collected data were statistically analyzed using Epi-info software version 6.04. Comparison between group means was done using student's $t$ test, whereas comparison between numbers was done by chi-squares test. Fisher exact test was used when indicated. The correlation between the clinical 
parameters of MS patients and the various measures of autonomic tests was analyzed with Spearman's correlation coefficient. The significance level was considered at $p$-value $<0.05$.

\section{Ethical issues:}

A verbal informed consent was obtained from all patients participated in the study after providing them with all the information regarding the study and they were informed that they could withdraw from the research at any time.

\section{Results}

We studied 20 patients with clinically definite remitting and relapsing Multiple Sclerosis (MS) $11(55 \%)$ males and nine (45\%) females] as well as 20 patients control groups.

The MS patients group had a mean age of $34.8 \pm 8$. 1 years with a range from 16 to 50 years, whereas the control group contained 20 healthy subjects (50\% males and $50 \%$ females) with a mean of age $34.2 \pm 13.4$ years. The duration of the disease ranged from one to eight years with a mean of 3.9 \pm 2.5 year; whereas, the mean of the EDSS scale was $4.1 \pm 1.5$ (ranged from 2.5 to 8 ) (Table 1). Regarding the dysautonomic symptoms, urinary dysfunction was the most frequent symptoms, which was encountered at some times during the illness in more than one thirds of the patients (45\%). The second most common symptoms was sexual disturbances, all of them were males, and orthostatic dizziness (20\% for each). No significant sweating or gastrointestinal impairment was reported in our patients. No one of the control group reported any dysautonomic symptoms. Using standard tests, nine patients showed abnormal blood pressure response to sustained handgrip, whereas one control subject showed abnormality in this test. Six patient showed abnormalities in blood pressure response to posture; whereas no control subject had abnormal test. Global analysis revealed that $13(65 \%)$ patients had at least one abnormal test. Five $(25 \%)$ patients had only one abnormal test and eight $(40 \%)$ patients had two or three abnormal tests. The control group showed tests abnormalities in two (10\%) patient.

The two groups differed significantly in the autonomic cardiovascular tests. In time domain analysis of $24 \mathrm{~h}$ ECG recording, no difference between the studied groups regarding the total processed time, whereas the mean heart rate (HR) was significantly higher in patients than control. $(p<0.001)$. The Max RR-Min RR intervals showed significant decline in the patients' group than in controls $(p<0.001)$. SDNN index, a broad measure of HRV, the PNN 50\% and RMSSD which measure the changes in the vagal mediated autonomic tone were significantly lower in the patients than in controls $(p<0.001)$ (Table 1$)$. As regards the correlation of autonomic dysfunction with clinical parameters, we found significant correlations between autonomic tests of sympathetic and parasympathetic systems with the duration of the disease. Weak correlation was detected between these tests and age of the patients. On the other hand, no relationship was found between autonomic dysfunction and both clinical severity of autonomic symptoms and EDSS (Table 2).

Table (1): Patients and control groups by demographic and clinical characteristic.

\begin{tabular}{llll}
\hline Data & $\begin{array}{c}\text { The patients } \\
\text { group }\end{array}$ & $\begin{array}{c}\text { The control } \\
\text { group }\end{array}$ & $\begin{array}{c}p \text { - } \\
\text { value }\end{array}$ \\
\hline Age & $56.9 \pm 6.4$ & $57.8 \pm 7.6$ & 0.6 \\
Gender: & & & \\
$\quad$ Female & $22(73.3 \%) /$ & $11(55 \%) /$ & 0.1 \\
$\quad$ Male & $8(26.7 \%)$ & $9(45 \%)$ & \\
Duration of disease & $23(76.7 \%) /$ & $14(70 \%) /$ & 0.6 \\
& $7(23.3 \%)$ & $6(30 \%)$ & \\
EDSS & $24(80 \%) /$ & $17(85 \%) /$ & 0.6 \\
& $6(20 \%)$ & $3(15 \%)$ & \\
Mean Blood pressure: & & & 000 \\
$\quad$ Systolic & $109.3 \pm 12.5 /$ & $124 \pm 7.5 /$ & $81.5 \pm 3.6$ \\
$\quad$ Diastolic & $69.6 \pm 7.6$ & $15(75 \%) /$ & 0.006 \\
Autonomic score & $28(93.3 \%) /$ & $5(25 \%)$ & \\
\hline
\end{tabular}

Table (2): Patients and control regarding by their autonomic nervous system alterations.

\begin{tabular}{llll}
\hline Data & $\begin{array}{c}\text { The patients } \\
\text { group }\end{array}$ & $\begin{array}{c}\text { The control } \\
\text { group }\end{array}$ & $\begin{array}{c}p \text { - } \\
\text { value }\end{array}$ \\
\hline Mean Blood pressure: & & & \\
$\quad$ Systolic fall on standing & $109.3 \pm 12.5 /$ & $124 \pm 7.5 /$ & 000 \\
$\quad$ Diastolic fall on standing & $69.6 \pm 7.6$ & $81.5 \pm 3.6$ & \\
& & & \\
Mean Blood pressure: & & & \\
Systolic rise on hand grip & $28(93.3 \%) /$ & $15(75 \%) /$ & 0.006 \\
Diastolic rise on hand grip & $2(6.7 \%)$ & $5(25 \%)$ & \\
24h ECG recording & $19(63.3 \%) /$ & $12(60 \%) /$ & 0.8 \\
(Parasympathetic): & $11(36.7 \%)$ & $8(40 \%)$ & \\
$\quad$ - Processed time (h) & & & \\
$\quad$ - Mean rate (beat/min) & & & \\
$\quad$ - RRI (ms) & & & \\
- MaxRR-MinRR & & & \\
- SDNN index (ms) & & & \\
$\quad$ - RMSSD (ms) & & & \\
- PNN 50\% & & & \\
\hline
\end{tabular}

Regarding the BAEP results, we found that:

1- Pure-tone and speech Audiometry showed within normal hearing levels in 16 patients, whereas four patients had minimal sensor neural hearing impairment (with no effect on BAEP). 
2- All subjects showed type A tympanometry; 14 showed absent acoustic reflexes elicited centrally; 4 showed elevated thresholds of acoustic reflexes; and two showed preserved reflexes at within normal range thresholds.

3- Individual test results: The prevalence of BAEP abnormalities was calculated using central group measures $\pm 2 \mathrm{SD}$ as an upper limit for normal values. Three patients showed normal BAEP findings; five patients showed very poor morphology with very poor repeatability in latency and amplitude measures; four patients showed only wave I with no BAEP waves after; and eight patients showed delayed absolute wave $\mathrm{V}$ latency with lengthening of I-V inter-peak latency. As regards the correlations of BAEP, there was a significant relation between autonomic tests and BAEP abnormalities (Table 3). We found also a significant correlation between autonomic score and I-V interpeak latency.

Table (3): BAEP abnormalities among patients with and without autonomic dysfunction.

\begin{tabular}{lcc}
\hline $\begin{array}{l}\text { BAEP abnormalities } \\
\%(\mathrm{No})\end{array}$ & $\begin{array}{c}\text { Patients with } \\
\text { autonomic } \\
\text { dysfunction } \\
\text { (No.=13) }\end{array}$ & $\begin{array}{c}\text { Patients } \\
\text { without autonomic } \\
\text { dysfunction } \\
\text { (No.=7) }\end{array}$ \\
\hline Present (17) & $13(100)$ & $4(57.1)$ \\
Absent (3) & $0(00)$ & $3(42.9)$ \\
Total & $13(100)$ & $7(100)$ \\
$p$ & $0.003 *$ & $0.003 *$ \\
\hline
\end{tabular}

BAEP: (Brain stem auditory evoked potential).

\section{Discussion}

Autonomic dysfunction is frequently observed in patients with MS, but clinical studies disagree on the frequency and type of abnormalities in autonomic function tests [13]. Evidence of two or more abnormal tests justifies the diagnosis of cardiovascular dysfunction [14] . In our study $40 \%$ of the patients had two or more abnormal cardiovascular tests. This figure closely resembles those reported by Briner et al., [15] Acevedo et al., [2] ; Gunal et al., [16] and Kodounis et al., [17] where $39.3 \%, 42.5 \%, 45.5 \%$ and $42.42 \%$ of their patients respectively had two or more abnormal cardiovascular autonomic tests. Flackenecker et al., [13] reported the same figure $40 \%$ and $39 \%$ respectively with at least one abnormal autonomic test. Stermann et al., [5] found that about one-half of their MS patients had two or more abnormal autonomic tests. Considering patients with one positive test (borderline), in our study, the percentage increased to $65 \%$. These findings are compatible with those of several previous studies in which more than half of the patients had at least one abnormal test Gallai et al., [18] (52\%); Acevedo et al., [2] (60\%); and de Seze et al., [19] (56\%). However, lower percentages $(27.5 \%, 25 \%$, and $27.3 \%)$ were reported by other authors; Vita et al., [14] . Frontoni et al., [4] and Merkelbach et al., [6] respectively. These differences could be attributed to different patient selection criteria, methods, clinical courses, and in-study medications. Furthermore, the frequency of abnormal findings in tests for $\mathrm{CV}$ autonomic nervous system varies due to the lack of standardized test performance or differentially used cutoff values [20] . Our MS patients showed a diminished autonomic responsiveness compared with healthy controls. The evidence of diminished sympathetic and parasympathetic activities in MS patients demonstrated by this study is in accordance with previous studies $[\mathbf{1}, \mathbf{2 , 1 9 , 2 1 - 2 4 ]}$. In the present study, sympathetic output was tested chiefly with two reflexes, BP response to standing and sustained exercise. Nine $(45 \%)$ patients and six $(30 \%)$ patients revealed an attenuation of blood pressure response to standing and exercise respectively, despite that only four $(20 \%)$ had abnormalities of both tests. The sympathetic dysfunction in MS patients was reported by Guibilei et al., [25], who postulated that statistically significant involvement of the sympathetic vasomotor system could be responsible for the orthostatic intolerance. Surprisingly, Monge-Argiles et al., [9], suggested that MS seemed to cause an increase in sympathetic cardiovascular tone and the authors explained this unexpected result to more habit in MS patients (and then relaxation) than in the control group for clinical examinations. Moreover, Frontoni et al., [4] found that the result of blood pressure changes to handgrip was the only result of the autonomic dysfunction tests in their study that could reach significance. Hilsted [26] has reported abnormalities in the blood pressure to exercise in patients with autonomic dysfunction of diabetic etiology. These changes were associated with a reduction in the catecholamine responses to exercise also. The blood pressure sustained handgrip in our study could be explained through a similar phenomenon. However, there is an alternative possibility which should be considered. Longhurst and Mitchell [27] have reviewed the role of different impulses originating from skeletal muscles in the regulation of heart rate and blood pressure during exercise. The "group IV afferents" are non-myelinated nerves which appear to respond to metabolites generated in skeletal muscle during exercise. Activation of these fibers results in a reflex tachycardia and an increase in blood pressure. Whilst the precise central connections of these fibers remain in doubt, it is widely 
believed that these afferent impulses are conveyed to higher centers in the posterior columns of the spinal cord. Heart rate variability (HRV) provides a quantitative evaluation of the sympathovagal interaction that modulates the autonomic function. Time domain variables are good indicators of parasympathetic tone, whereas the frequency variables measure the sympathetic activity [9]. In the present study, time domain parameters diminished in MS patients compared with control denoting decreased parasympathetic tone. Forty-eight percent of MS patients in a study of Gallai et al., [18] had abnormal values in deep breathing test, indicating failure of the parasympathetic function. Monge Argiles et al., [9] analyzed the HRV in time and frequency domains in 34 MS patients. Variability in time domain was lower in most of MS patients denoting affection of the parasympathetic tone. Flachenecker et al., [1] assessed the cardiovascular autonomic dysfunction in 26 patients with MS. Parasympathetic dysfunction was found to be closely related to progression of disability and in contrast, sympathetic dysfunction was associated to the clinical activity. Regarding the correlation of autonomic dysfunction with clinical parameters, we found significant correlations between autonomic tests of sympathetic and parasympathetic systems with the duration of the disease. Weak correlation was detected between these tests and age of the patients. It is well known that most autonomic function decrease with age. Thus we could not determine whether diminished autonomic reactivity found in our patients attributed to age or to progressive damage caused by MS itself. Frontoni et al., [4] found that a progressive decrease of total power spectral density (PSD) of HRV has been correlated with an increasing age; however they postulated that the length of the illness rather than the age of the subjects seemed to influence the PSD. On the other hand, no relationship was found between autonomic dysfunction and both clinical severity of autonomic symptoms and EDSS. Clinical correlations of autonomic tests dysfunctions have been a subject of controversy among authors. In agreement with miscorrelation between autonomic test and severity of autonomic symptoms, Stermann et al., [5] detected that 22 patients with MS did not report specific autonomic symptoms despite that about one-half of their patients had two or more abnormal autonomic tests, and they hypothesized that abnormal function might be masked by other disabilities and therefore difficult to appreciate without specific testing. Flachenccker et al., [1] found that parasympathetic but not the sympathetic dysfunction increased slightly during follow up period with a significant correlation to the increase in clinical severity. Cardiovascular dysfunction was slightly related to age and to EDSS in a study done by Merkelbach et al., [6] . Gunal et al., [16] with statistical analysis of 22 patients with relapsing remitting MS indicated that patients with long disease duration rather than high EDSS carried a risk of autonomic involvements in MS. In contrast, Acevedo et al., [2], in a study on 40 patients with MS, demonstrated the relation between autonomic dysfunction and clinical deterioration (as expressed by values of the EDSS and FIM scales). In the present study different types of BAEP abnormalities were observed in MS patients. Poor morphology including very poor repeatability in latency and amplitude measures and absence of all waves except wave I as well as prolongation of absolute latency of wave $\mathrm{V}$ and prolongation of interpeak latency I-V, which indicated brainstem affection. They stated that variable BAEP abnormalities found might indicate different demyelinating patches affecting different sites of brain stem which affect proper synchronization of neural fibers sufficient to generate BAEP waves in normal measures. As regards the correlation between autonomic tests and BAEP; We found significant correlations between I-V interpeak latency with autonomic score. To best of our knowledge, this topic is not a matter of frequent research.

\section{Conclusion:}

Based on the results of the study, it was concluded that a significant number of patients with MS show evidence of CV autonomic dysfunction, which is correlated with brain stem function. Thus, the autonomic tests could be a useful tool for detecting subclinical autonomic dysregulation and hence, developing more effective treatment and rehabilitation strategies.

\section{References}

1- FLACHENECKER P., REINERS K. and KRAUSER H.: Autonomic dysfunction in multiple sclerosis is related to disease activity and progression of disability. Multiple Sclerosis J., 9 (7): 327-334, 2001.

2- ACEVEDO A.R., NAVA C. and ARRIADA N.: Cardiovascular dysfunction in multiple sclerosis. Acta. Neurol. Scand J., 3 (101): 85-88, 2000.

3- HAENSH C.A. and JORG J.: Autonomic dysfunction in multiple sclerosis. J. Neurol., 253 (Suppl I): i3-i9, 2006.

4- FRONTONI M., FIORINI M. and STRANO S.: Power spectrum analysis contribution to the detection of cardiovascular dysautonomia in multiple sclerosis. Acta. Neurol. Scand J., 5 (93): 241-245, 1996.

5- STERMAN A.B., COYLE P.K. and PANASCI D.J., GTIMSON R.: Disseminated abnormalities ofcardiovascular autonomic functions in multiple sclerosis. Neurology J., 8 (35): 1665-1668, 1985. 
6- MERKELBACH S., DILLMANN U. and KOLMEL C.: Cardiovascular autonomic dysregulation and fatigue in multiple sclerosis. Mult. Scler. J., 2 (7): 320-326, 2001.

7- SAARI A., TOLONEN U. and PAAKKO E.: Cardiovascular autonomic dysfunction correlates with brain MRI lesion load in MS. Clin. Neurophysiol. J., 9 (115): 14731478,2004

8- HAAPANIEMI T.H., PURSIANEN V. and KORPELAINEN J.T.: Ambulatory ECG and analysis of heart rate variability in Parkinson's disease. Neurol. Neurosurg. Psychiat. J., 3 (70): 305-310, 2001.

9- MONGE-ARGILES J.A., PALACIOS-ORTEGA F., VILA-SOBRINO J.A. and MATIAS-GUIU J.: Heart rate variability in multiple sclerosis during a stable phase. Acta. Neurol. Scand J., 10 (97): 86-92, 1998.

10- HUIKURI H.V.: Heart rate variability in coronary artery disease. J. Int. Med., 7 (237): 349-357, 1995.

11- FILIPPI M., PATY D.W. and KAPPOS L.: Correlations between changes in disability and T2- weighted brain MRI activity in multiple sclerosis: A follow-up study. Neurology, 5 (45): 255-260, 1995.

12- POSER C.M., PATY D.W. and DAVIS F.: New diagnostic criteria for multiple sclerosis. Ann. Neurol. J., 3 (13): 227-231, 1983

13- FLACHENECKER P., WOLF A. and KRAUSER M.: Cardiovascular autonomic dysfunction in multiple sclerosis: correlation with orthostatic intolerance. J. Neurol., 9 (246): 578-586, 1999.

14- VITA G., FAZIO M.C. and MILONE S. :Cardiovascular autonomic dysfunction in multiple sclerosis is likely related to brain stem lesions. J. Neurol. Sci., 2 (120): 8286, 1993.

15- BRINER V., BRZOVIC Z. and PAPA J.: Autonomic function in patients with multiple sclerosis. Coll. Antropol. J., 1 (21): 493-497, 1997.

16- GUNAL D.., AFSAR N., TANRIDAG T. and AKTAN S. Autonomic dysfunction in multiple sclerosis: Correlation with disease-related parameters. Eur. Neurol. J., 6 (48): $1-5,2002$.

17- KODOUNIS A., STAMBOULIS E., CONSTANTINIDIS T.S. and LIOLIOS A.: Measurements of autonomic dys- regulation in multiple sclerosis. Acta. Neurol. Scand J., 7 (112): 403-408, 2005.

18- GALLAI V., SARCHIELLI P. and FIRENZE C.: Neuropeptide Y plasma and serum levels dopaminebetahydroxylase activity in MS patients with and without abnormal cardiovascular reflexes. Acta. Neurol. Belg. J., 4 (94): 44-52, 1994.

19- De SEZE J., STOJKOVIC T. and GAUVRIT J.Y.: Autonomic dysfunction in multiple sclerosis: Cervical spinal cord atrophy correlates. J. Neurol., 2 (248): 297-303, 2001.

20- MERKELBACH S., HAENISH C.A. and HEMMER D.: Multiple sclerosis and autonomic nervous system. J. Neurol., 9 (253 Supp I): I21-25, 2006.

21- NASSERI K., UTIDEHAAG B.M. and WALDERVEEN M.A.: Cardiovascular autonomic function in patients with relapsing remitting multiple sclerosis: A new surrogate marker of disease evolution, J. Neurol., 2 (6): 29-33, 1999.

22- KESELBRENER L., AKSELROD S. and AHIRON A.: Is fatigue in patients with multiple sclerosis related to autonomic dysfunction. Clin. Auton. Res. J., 7 (10): 169175,2000 .

23- MONGE-ARGILES J.A., PALACIOS-ORTEGA F., VILASOBRINO J.A. and MATIAS-GUIU J.: Autonomic cardiovascular dysfunction in multiple sclerosis not caused solely by brain stem lesions. Rev. Neurol. J., 8 (;34): 1119-1123, 2002

24- BREZINOVA M., GOLDENBERG Z. and KUCERA P.: Autonomic nervous system dysfunction in multiple sclerosis patients. Neurology J., 2 (105): 404-409, 2004.

25- GIUBILEI F., VITALE A. and URANI C.: Cardiac autonomic dysfunction in relapsingremitting multiple sclerosis during a stable phase. Eur. Neurol. J., 10 (36): 211-214, 1996.

26- HILSTED J.: Pathophysiology in diabetic autonomic neuropathy: Cardiovascular hormonal and metabolic studies. Diabetes J., 4 (31): 730-737, 1982.

27- LONGHURST J.C. and MITCHELL J.H.: Rreflex control of the circulation by afferents from skeletal muscles. In: Guyton A.C., Young D.B., eds. International review of physiology, cardiovascular physiology III, Vol. 18., Baltimore: University Park Press, 125-148, 1997. 


\section{التغييرات التى تطرأ على الجهاز العصبى الودى والمجاور للودى التوفي لمرضى التصلب اللوحى التى الودى}

المقدمة: يعتبر مرض التصلب اللوحى من الأمراض العصبية للجهاز الحركى والذى قد يؤدى إلىإعاقة كاملة للمصاب. تهدف هذه الدراسـة: إلى تقييم مدى التفييرات التى تطرأ على الجهاز العصبى الودى والمجاور للودى لدى مرضى التصلب اللوحى.

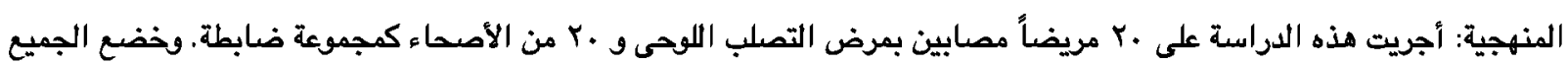

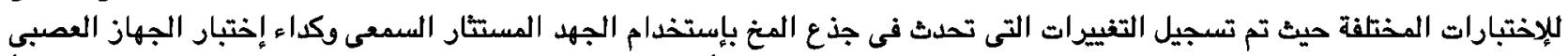

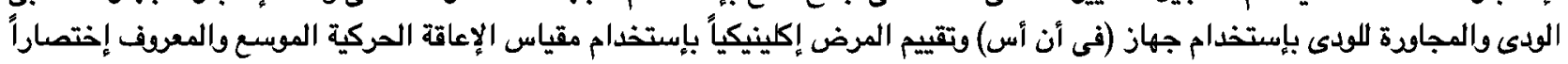

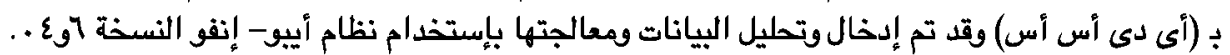

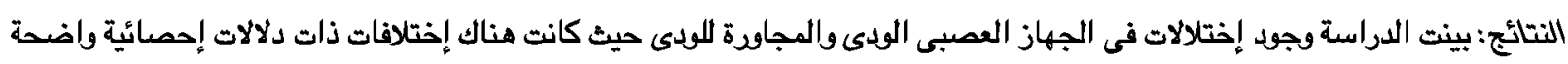

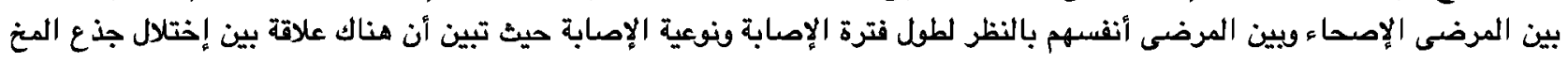
وأضطراب الجهاز العصبى الودى والمجاودة للودئ.

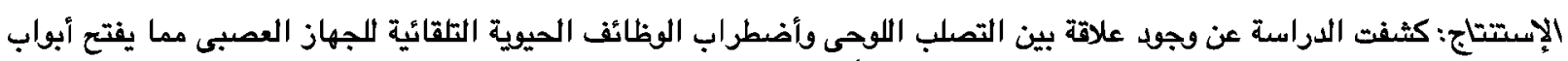

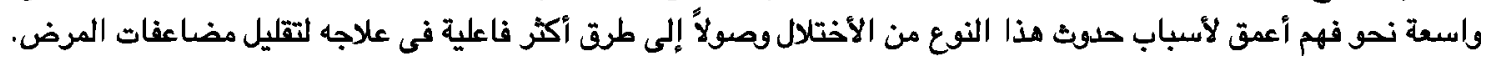

